\title{
A Farewell Note
}

With the publication of this issue, my tenure as Editorin-Chief for the Journal of Biomedical Science (JBS) comes to an end. It will conclude more than a decade of association with this journal, during which I had the privilege of witnessing first hand the struggle, soul-searching, exhilaration and dejection during the development of $J B S$. It is my understanding that this will also be the last issue of $J B S$ to be published by the House of Karger. I view this episode with deepest regret because the congenial partnership between $J B S$ and S. Karger will likewise come to an end.

In the Editorial that I wrote for our 'Special Issue to Commemorate the 10th Anniversary of the Journal of Biomedical Science' [1], I have already shared, for the record, my thoughts on the past, present and future of $J B S$. What I would like to add are two principles that I have adopted during the past 8 years as the Editor-in-Chief. First, JBS is about science. Our editorial deliberations are always based solely on the quality of science. To this end, I deemed it my responsibility to shield $J B S$ from non-scientific, including political, interference. Second, JBS is about people. My personal conviction is that ours is a medium for budding biomedical scientists in Asia to introduce their work to the international community. As long as the science is acceptable, it is not unusual that we would try our best to process expediently a submitted manuscript or to publish an accepted article to meet the deadline of young authors.

My most sincere appreciation goes to Prof. C.C. Chang, our Founding Editor-in-Chief, who entrusted me with $J B S$ when he decided to pass the baton. My wholehearted appreciation also goes to Tom Karger, whose personal attention allows our relationship with S. Karger one of cordial partnership. I am also indebted to our former and current Editorial Board members and our Regional Editors. Their efforts and dedications are pivotal to making $J B S$ where we are. The continuous support and advice from our Advisory Board members are deeply appreciated. The dedication of our former and current Assistant Editors, Ms. T.L. Yang and Ms. T.J. Hsu in the Editorial Office, and Rolf Steinebrunner, Pamela Koppay and Deborah Lautenschlager in S. Karger, in the production of $J B S$ makes this project my most enjoyable professional experience. Last, but not least, I am most grateful to the authors who have supported our journal with highquality manuscripts, and the reviewers who have helped us in maintaining a high standard.

As I prepare this farewell note, the lyrics of the song 'My Way' popularized by the late Frank Sinatra resonate in my mind. In particular, 'Regrets, I had a few; but then again, too few to mention. I did what I have to do, and did it all without exemption ... I did it my way.'

It has been an honor and tremendous privilege to serve as your Editor-in-Chief.

\section{Reference}

1 Chan SHH: For the record. J Biomed Sci 10:567-568;2003.

\begin{tabular}{ll}
\hline KARGER & (c) 2004 National Science Council, ROC \\
Fax +41613061234 & 1021-7770/04/0116-0710\$21.00/0 \\
E-Mail karger@karger.ch & $\begin{array}{l}\text { Accessible online at: } \\
\text { www.karger.com/jbs }\end{array}$ \\
www.karger.com & war.
\end{tabular}

